\title{
Towards An Effective Collaboration Between South Western Sydney Local Health District and Local Councils: Insights From The Qualitative Study
}

\section{Vilas Kovai ( $\square$ Vilas.Kovai@health.nsw.gov.au )}

South Western Sydney Local Health District Population Health https://orcid.org/0000-0002-2672-9970

\section{Zeenat Mahjabeen}

University of New South Wales - Kensington Campus: University of New South Wales

\section{Punitha Arjunan}

South Western Sydney Local Health District Population Health

\section{Bin Jalaludin}

South Western Sydney Local Health District Population Health

\section{Research}

Keywords: Built environment, Collaborations, Councils, Evidence-based local data, Engagement, Population Health, Policy, Qualitative research, Urban Planning

Posted Date: June 17th, 2021

DOl: https://doi.org/10.21203/rs.3.rs-600209/v1

License: (9) (1) This work is licensed under a Creative Commons Attribution 4.0 International License. Read Full License 


\section{Abstract \\ Background}

Urban planning is of fundamental use in promoting a healthy urban environment, prompting increased collaboration between public health and local government planning authorities. A major challenge to the success of this co-operation, however, is the difficulty of ensuring that the views of the health sector are, ultimately, reflected in planning policy. To facilitate this, a qualitative study was designed by Population Health, South Western Sydney Local Health District (SWSLHD) in 2016.

\section{Objective}

The aim of the study was to investigate ways in which SWSLHD could be engaged with councils in the urban planning processes of local councils in south-western Sydney to promote a healthy urban environment.

\section{Methods}

Qualitative data was collected from 14 in-depth interviews with staff representing five local councils: Bankstown, Camden, Liverpool, Campbelltown, and Fairfield. The data was thematically analysed using inductive and deductive reasoning by applying NVivo software.

\section{Results}

While councils recognise the potential value of consultation (and partnership) with SWSLHD, the fact is that the status quo is one of limited communication and the absence of any clearly defined process for collaboration. Councils perceive knowledge gaps in relation to basic issues such as who provides what services to whom and how to access services from health experts related to evidence based local government level data.

\section{Implications:}

The study demonstrated that a shift in provision of public health evidence that has local applicability in a timely manner on issues of mutual concern, and proactive and ongoing consultations between SWSLHD and councils would enable effective engagement, coordinated and sustained actions.

\section{Introduction}


The physical environment in which people live, work and play is a product of both objective and subjective features of the built and natural environment (1). The suggestion that the way we design our environment has implications for our health is not a new proposition, but it is one that is worthy of serious reflection. The volume of literature published on the topic in the last decades is considerable (27), highlighted the need for strong collaborative partnerships between public health and planning professionals. Skills-sharing and co-investment in research and innovation have become crucial in the delivery of those benefits which allow communities to flourish and fulfil their potential.

The New South Wales Healthy Built Environment Checklist was developed to ensure effective engagement between health and planning professionals and support the development of well-connected, liveable and sustainable communities (3). Items on the checklist relate to healthy eating, physical activity, housing, transport and connectivity, quality of employment, safety and social cohesion/connectedness in relation to risk factors and social determinants, and whether or not these factors have been considered in the drafting of a given community development policy, plan or proposal. From a health perspective, checklist items have been included for the primary purpose of addressing chronic diseases, the leading causes of ill health, thereby reducing health risks and improving health outcomes in the community.

Evidence shows that the built environment (the humanly-constructed part of the world we live and work in) influences multiple modifiable social determinants of health, including access to employment, education and healthcare $(7,8)$. For example, increased access to walking and cycling infrastructure, greenspace, community infrastructure, and transport options has the potential to improve opportunities of living a healthy life $(1,9)$.

In the state of New South Wales (NSW), local government areas (LGAs) act as a third tier of government, with local authorities (Councils) accountable for the planning, design and implementation of works related to the built environment of their communities (10). Councils have responsibility for the provision of a wide range of community services, including services related to health, community connection, transport and access, training and education, culture and recreation(10). In short, as mentioned, the built environment, has a significant role to play, both directly and indirectly, in the health of communities $(1,7)$ Hence, a coordinated and sustained action through partnerships between councils and SWSLHD and other sectors is crucial to maximise the health outcomes for their communities $(11,12)$. However, limited relationship with local councils within its jurisdiction and lack of opportunity were highlighted in a study assessing SWSLHD's influence on planning policy (13). Moreover, existing research (7) and internal discussions at the Population Health meetings of SWSLHD emphasise the need to further explore partnership opportunities and the possibility of standardising the process of consultation and negotiation.

To gain better insight into the extent and effectiveness of partnership between councils and SWSLHD, a qualitative study was conducted by SWSLHD's Population Health unit in 2016, with staff involved in policy development at local councils. The study aimed to investigate how SWSLHD could be effectively 
involved in the urban planning process of local councils, and thereby promote a healthier urban environment.

\section{Methodology}

This paper is based on an analysis of in-depth interviews with local council staff involved in the development of policy relating to urban, local environmental, and community development. The study participants were selected on the basis of their suitability to answer the study questions. The purpose of using in-depth interviews, in this study, was two-fold: first, to obtain comprehensive information on the topic of interest, and second, to attempt to elicit additional information by asking follow-up questions. This study was approved by the Human Research Ethics Committee of South Western Sydney Local Health District (HE 16/069 LNR). The consolidating criteria for reporting qualitative research (14) was used to report the important aspects of the study methodology reported in this paper.

The Population Health Unit's steering committee and study team provided advice on the implementation of the study and the necessary recruitment process. In-depth interviews were conducted with staff from five of the SWSLHD's seven local councils, namely Camden, Liverpool, Campbelltown and Fairfield. The Wollondilly Council and the Wingecarribee Shire Council were excluded from the study for logistical reasons.

An open-ended tool to guide the interview process was developed through the literature review and discussion with the study team (Table 1). The topic guide for the interview included the following major themes: scope for SWSLHD's involvement in the councils' built-environment planning process and the barriers and enablers to the effectiveness of that involvement. 
Table 1

Open ended guide for in-depth interviews

\section{Domain Open ended question}

Exploring the opportunities

Using the opportunities

Exploring and analysis of the factors of effective use of the opportunities
What are the formal and informal opportunities for providing input? (Discussion about opportunities outlined in the environmental planning policies and any opportunities which are not outlined in the policies).

In what stages of the planning process is SWSLHD invited to provide input and what other health related stakeholders are also invited to provide inputs?
When SWSLHD is invited to provide input what are the other things local councils provide them with the draft plan (like information package)

b. Perception in the Local Councils

How important do the local councils think it is to consult SWSLHD before a plan is made? How the submissions are analysed and decided - what are the factors considered?

\section{c. Problems in accepting the inputs}

What are the problems local councils face in accepting/incorporating SWSLHD's input into plans? How can they be addressed? If there is any, further discussion on the reasons.

\section{d. Benefits/ level of satisfaction}

What are the benefits the local councils think they are getting if SWSLHD is consulted? (May be increase of knowledge/skill, better relationship, and plan quality).

\section{a. Communication}

How comfortable are local councils to deal/communicate with the SWSLHD. Reasons for the opinion. What are the informal avenues of communication, if there are any, how often and whether that help?

b. Issues of accountability (transparency/access to information/integrity)

Whether SWSLHD is provided with feedback after plans are finalised - such as, what happens with their input, how much has been adopted or not and why.

Towards more healthy urban plans
Is the way SWSLHD provides input helpful or useful? If yes, how can be more improved? If no, why not? What are the steps or policy alternatives local councils think should be which can help them in planning for a better health supportive urban environment.

General Managers of the nominated local councils were approached by a study investigator via phone and an email containing a letter from the Director of Population Health and a Participant Information Sheet. The letter explained the purpose of the study and requested the participation of local council staff involved in the development of policy planning and program implementation. This was then followed by a phone call from the principal investigator, seeking the willingness of councils to participate. Five 
councils responded within two weeks, expressing their willingness to participate and listing the contact details of potential interviewees. Study investigators then followed up by contacting each of the recommended staff members by email or phone, seeking an appointment.

Once interviewees had consented and indicated the times of their availability, appointments were made. Before each interview, a participant consent form was signed and collected. Investigators with prior experience of conducting qualitative studies conducted fourteen face-to-face interviews at the council chambers. The duration of the interviews ranged from 45 to 60 minutes, and all were audio-taped and later transcribed verbatim by professional transcribers. Ethics approval was obtained from the South Western Sydney Local Health District Human Research Ethics Committee.

\section{Data analysis}

The six steps of thematic analysis proposed by Braun and Clarke(15) were followed for data analysis. The data was coded using open and axial methods. One of the researchers (VK), in consultation with another researcher (ZM), developed an initial coding scheme consisting of themes, subthemes, and their definitions. Working independently, both researchers coded the data from three interviews and then evaluated the success of the coding process and findings. By so doing, they were able to enhance coding consistency and refine the coding framework, which was subsequently used for the data analysis of the 14 interviews. Finally, the researcher (VK) independently performed the data analysis using both inductive and deductive reasoning by applying the NVivo version10 (QSR International, Doncaster, Vic., Australia) (16). The open codes of data were merged into relevant categories, then into initial themes and finally, the initial themes were reduced to a few major themes using the axial coding process.

\section{Results}

\section{Participants}

The results are based on an analysis of data from in-depth interviews with 14 participants from five of the seven local councils in SWSLHD (Table 2). The participants are all staff (officers, managers and team leaders) from various Council departments, including: Asset management for Open Space and Property $(n=1)$; Community Resources and Development $(n=1)$; Strategic Planning $(n=6)$; Recreation and Open Space Planner $(n=1)$; Spatial Planning $(n=1)$; Community Safety and Crime Prevention $(n=1)$; Sports and Recreation $(n=1)$; Development Planning $(n=1)$; Urban Policy and Planning and group manager $(n=$ 1). 
Table 2

Details of Participants from councils

\begin{tabular}{|c|c|c|}
\hline $\begin{array}{l}\text { Name of the } \\
\text { councils }\end{array}$ & $\begin{array}{l}\text { Number of } \\
\text { interviews }\end{array}$ & Role of participants in local councils \\
\hline \multirow[t]{2}{*}{ Bankstown } & 3 & Manager of Spatial Planning \\
\hline & & $\begin{array}{l}\text { Community Safety and Crime Prevention Officer Team leader for } \\
\text { Urban Policy and Planning open space planning }\end{array}$ \\
\hline \multirow[t]{2}{*}{ Camden } & 3 & Strategic Planner \\
\hline & & Strategic Planner Team leader of Growth Areas \\
\hline Liverpool & 2 & Manager of Strategic Planning Recreation and Open Space Planner \\
\hline \multirow[t]{3}{*}{ Campbelltown } & 4 & Manager of Community Resources and Development \\
\hline & & Sport and Recreation Coordinator \\
\hline & & Strategic Planning Unit Development planner \\
\hline Fairfield & 2 & Manager of city assets Group Manager, Governance and Community \\
\hline Total & 14 & \\
\hline
\end{tabular}

\section{Themes}

The results are grouped into two major themes, with the details of sub-themes presented in Table 3 . The organisation of results is such as to explain (1) the opportunity and scope of engagement between councils and SWSLHD, and (2) the enablers of effective engagement between the Councils and SWSLHD.

Table 3

Details of Themes and number of references

\section{Themes}

No of references

(1). The opportunity and scope of engagement between councils and SWSLHD

38

Sub-Theme 1: Knowledge about benefits of community engagement

Sub-Theme 2: Scope for engagement of SWSLHD with Councils

(2). The enablers for effective engagement between councils and SWSLHD 38

Sub-theme 1: Provide evidence-based information on local communities 69

Sub-theme 2: How to improve communication between the Council and SSLHD

Theme 1: the opportunity and scope of engagement between SWSLHD and Councils 
This theme explains participants' insight into the benefits of engagement with SWSLHD and their views on the scope of such an engagement.

\section{Insight into the benefits of engagement}

This sub-theme consists of a total of 35 references. Participants acknowledged that consultation with relevant stakeholders provides a better understanding of an issue they want to deal with and helps to generate different perspectives on proposed solutions. In addition, the consultation process helps to identify potential partners for the planning and implementation of proposed activities. Moreover, because of the nature of the partnership itself and the expertise of those involved, the activities are significantly more likely to be evidence-based and with a greater potential to engage the community, thereby increasing the likelihood of enhancing the social and health outcomes.

"[partnership provides] more of that human perspective... We [from a Council view] are looking at a patch of land rather than looking at an issue like health ...[but] councils only exist for people... [and] sometimes that gets forgotten because we do have a very strong engineering focus; we have a very strong focus on plans, on maps and all that kind of thing ... So, I think the Local Health District is important to bring back the people focus.

\section{Scope of SWSLHD's engagement with Councils}

This sub-theme consists of a total of 42 references relating to the scope of engagement. Participants view the goals of the health sector and those of Council as having significant overlap, hence the need for consultation to discuss plans, strategies and activities, in order to achieve better health outcomes for residents.

"... if health had a different perspective and they had different ideas of what they wanted to do and they were contrary to what we were trying to do, it wouldn't potentially work or may take some time to work out what to do; but currently there is a lot of overlap, like a serious amount of overlap".

Further, participants agreed that while the main aim of Councils is to design appropriate activities to engage community members, their activities also contribute to secondary outcomes such as social and health benefits that promote health.

"Our primary driver is not necessarily the health of the community; it's more the engagement of the community in the activities they want to do. [Partnership with SWSL HD] certainly gives you other health benefits and it certainly gives you social benefits".

Explaining further, participants considered that, as health is integrated into the work Councils do, there is a mutually advantageous opportunity for SWSLHD and Councils to engage with each other. An example of this is Councils' activities around the 'built environment', such as designing and developing buildings, city centres, footpaths, gyms in parks, leisure centres, childcare centres. The existence of such facilities tends to encourage communities to become more physically active-such as walking, cycling and 
exercising in a variety of ways. These activities could potentially contribute to community-level health promotion, both in terms of the built environment and as a means of addressing the social determinants of health.

"We don't deliver direct health services but we put gyms in parks; we run gym programs, leisure centres, childcare centres and everything we do touches on health both environmentally and in the social determinants or the risk-factor behaviour stuff as well'.

They consider collaboration between urban planners and Health Promotion services as essential, because-

"The urban design issue is a really important one, and then how that interacts with activity, so whether it's sporting or just people being physically active or how easy it is for people to access transport, there are a lot of issues around urban design that are critical to us".

So, within this context, participants suggested that it was imperative for Councils to partner with SWSLHD in the design and delivery of appropriate activities. Equally important to the success of the planning process is the timing of the engagement with SWSLHD (and other relevant stakeholders).

\section{Theme 2: Enablers for effective engagement}

This theme explains the enablers that make possible an effective engagement between SWSLHD and councils. The required enablers are: evidence-based information on effectiveness of community based programs; improved community engagement; and improved communication between SWSLHD and councils.

\section{Evidence on effectiveness of community-based programs}

This subtheme consists of 38 references and presents the expectation of councils with respect to partnership with SWSLHD. Participants agreed that there was a dearth of evidence on various aspects of planning about the community-based programs and their health benefits, a gap which it is hoped the SWSLHD can help to fill. Councils, meanwhile, have limited access to local data on effectiveness of smoking cessation programs, relationship between increased access to healthy food and physical environment and health outcomes, access to wellbeing programs that reduce risks from consumption of alcohol, gambling practices, etc. Therefore, before they can deliver appropriate programs, councils need clear and succinct evidence-based information about the local community. As emphasised by one participant:

"They (SWSLHD) need to do more research so we can do evidence-based planning, because, at the moment, we get very little local data. There is some. You can get some hospital data but we don't get locally applicable data on smoking interventions [rates], data around increase access and engagement opportunities that increase physical activity; food environment and its association with improved 
consumption of fruits and vegetables and health outcomes. The current state or national data is not enough to help with our planning cycles"

Participants' viewed that evidence-based information would also help the Council to support its decisions in the situation of competitive interests. For example, as one participant explained:

"One thing health could do would be to give us evidence on the social impact of gambling practices so that we can stand up. Councils approve applications for gambling [licenses] because we don't have data to make decisions to stop them. Often, our hands are tied by the rules set by the state government"

\section{Evidence on effectiveness of community engagement programs}

Likewise, participants identified social engagement as an important area of work which requires evidence-based information if it is to be boosted, thereby increasing utilisation of such things as sports programs and recreation facilities. This relies on assistance from SWSLHD, as mentioned:

"Social engagement is the biggest problem, whether it be in sport, recreation or whatever, especially in Campbelltown. So, helping us engage with the community and giving us more access to evidence are probably the two areas in most need of attention."

\section{Improve communication between the Council and SWSLHD}

This sub-theme consists of a total of 69 references from participants. The theme presents findings on how to improve communication between the Council and SWSLHD, particularly as it relates to proactive co-operation with planning department and developing stronger relationships overall.

\section{Proactive liaising with the department of planning:}

Rather than waiting to provide input during the public -notification and submission-invitation periods, the SWSLHD can proactively communicate with relevant council staff whenever they have cause, especially in the early stages of planning. Such involvement of relevant stakeholders is not only critical, it is also highly mutually beneficial.

"Where I see a space for you guys is, and that is from the submission perspective, which is one thing, but where I see a space is in terms of providing the evidence-base early, so that, rather than waiting for submissions to be called, be proactive and think about the needs of a community. That means looking at Camden 20/40, our community strategic plan, and then looking at different actions associated with that and maybe providing the evidence and research that could help make a real difference on the ground .

Hence, the SWSLHD needs to liaise with Council planning departments which may open even broader and deeper channels of engagement and connection with Councils. Attending monthly council meetings (including district-level planning meetings, such as forums like WSROC (Western Sydney Regional Organisation of Councils) could be another step towards understanding the nature of the work of Councils, their requirements and how stakeholders can be part of the engagement process. Participants 
also suggested that, in addition to seniors, the attendance and participation of lower and middle-level staff at such meetings might also be useful.

As mentioned earlier, proactive engagement, apart from formal meetings, is critical to establishing an effective collaborative relationship, particularly one with a view to promoting community health:

"You need to have formal and informal meetings and you need it at an executive level or managerial level, but you also need it between".

Participants indicated that in some situations, additional individual meetings with partners are organised to clarify issues of concern (emerging from initial consultations) to build consensus and working relationship. From time to time other options may also arise:

"There are often crossovers between, say, yourself and a different agency, or an issue someone else has that is going to impede being able to deliver what you want. So, we have that discussion and, later on, it's often resolved through an individual meeting, and it's easier to organise a meeting with one other than with 15 agencies".

In summary, participants viewed that the feedback from stakeholders is assessed in terms of the value they, as partners, can add to the proposed plans or activities and whether they fit into the available resources. Needless to say, the feedback must be precise and evidence-based:

"I suppose the relevance, whether or not the concerns are being addressed, and whether it offers an objection or provides support, which is the key. We also have to look at how it fits with our policy decision making to see whether there are synergies there."

For SWSLHD to make a meaningful input, one participant advised specificity:

"So, if you are providing feedback on a review of a Local Environment Plan for example, and I suppose we would benefit from evidence-based research, we would prefer less broad statements".

\section{Stronger Relationship}

Participants acknowledged that both Councils and the Local Health District need to work on building and maintaining stronger relationships to achieve an effective outcome from the formal consultation process. In this context, they urged having a contact person (s) in the Local Health District who could be regularly engaged with councils, as well as easily contactable for information and updates, without necessitating the typically gratuitous rigmarole so often entailed by bureaucratic processes

"Probably the best way to do it would be to give us a contact officer within the department, someone we could go to and seek advice from the relevant authority, and someone who engages with us regularly".

\section{Discussion}


The study investigated opportunities for SWSLHD to engage with councils within its jurisdiction and identified approaches to more effective collaboration. The three main approaches discussed are: providing local governments with evidence-based data in a timely manner; integrating the goals of the SWSLHD with those of Councils; and, regular ongoing and proactive communication between SWSLHD and councils.

The findings suggest that Councils' demand for evidence-based information on communities living within their Local Government Area (LGA) has been largely unmet, a finding echoed in other studies $(5,17)$. Our results agree with the findings of recent research (1) that good quality evidence on association between provision of healthier and affordable food in diverse settings (e.g., super markets, schools, workplaces) and improved consumption of fruits and vegetables; association between increased access and engagement opportunities (e.g., increase infrastructure for walking and cycling) and improved physical activities is crucial. Whereas national- or state-level data is available, there remains a paucity of highquality, LGA-level data that could be used to enable strategic and tactical decision-making, particularly in situations of competing budget priorities. For example, a recent systematic review by Bird et al, (1), identified a wealth of national and global level evidence on the associations between improved food and physical environment and their association with improved health outcomes (e.g., improved diet behaviours and weight related outcomes). Such evidence, however, still needs to be tested on local populations and translated to local government level as echoed in this study and a recent study (5).

The results indicate, moreover, that timely information about the health concerns of local communities and their health practices including improvement in community engagement of built physical environmental facilities (such as sports facilities and parks) would not only support councils in making complex, policy-focussed decisions, but also contribute to better engagement with council services. Hence, in consensus with other studies $(5,17)$, our findings advocate for a SWSLHD policy shift in the provision of public health evidence that has local applicability to support address funding decisions of councils.

In addition, the study finds that coordination of relevant organisational-level policies and programs between the SWSLHD and Councils is essential for the appropriate design and delivery of food and physical environmental plans and programs. This notion has been manifested in previous studies; for example, evaluation of The Make Healthy Normal, obesity prevention mass media campaign of NSW government (4), and evaluation of the Healthy Eating Active Living program of the Victorian Government through Council-operated sports and recreation facilities(18). Indeed, the number and variety of Council partnerships-with organisations representing Education, Transport, Police and Health is such that, where possible, the timely and effective leadership provided by the SWSLHD is critical.

The study further finds that maintaining an effective relationship between Councils, SWSLHD and relevant other stakeholders from the inception of a project increases the likelihood of a successful, preventive health effort. The results, consistent with the 'five conditions of collective impact' proposed by Preskill, et al (19), highlight the (unmet) need for proactive and ongoing communication between 
SWSLHD and Councils. Such communications are crucial for multiple reasons: to understand a shared vision for change; to clarify issues of mutual concern; to collect evidence-based data reflecting the needs of councils; to build consensus, maintain sustainable relationships and achieve collective impact.

In short, the indications are that consultation with planning departments, and participation in formal and informal periodic meetings with all levels of management is essential for understanding the nature of how Councils operate and, importantly, how SWSLHD can be part of the engagement process. This is consistent with the recommendations of other studies, which suggest that Local Government is an underutilised resource in the context of effective and efficient population health planning $(2,3,6,17)$. Furthermore, Federal Government policies and guidelines typically fail to provide clear recognition of the values of collaboration with non-health sectors and instruction on how best to engage (6). The results confirm that establishing ongoing relationship among the including key SWSLHD management staff member(s) who regularly liaise with local councils and monitoring by the leadership of SWSLHD is the best way to address communication gaps and increase potential for effective collaboration with Councils. In this way, Councils also gain better into the nature and scope of SWSLHD Population Health programs (5). As reflected by Janzen et al (11), a refocus on health equity could enable to engage both SWSLHD and councils.

The fact that data was collected from a single source, and not triangulated using other sources (e.g., consultations with political and other community-based stakeholders), is a major limitation of this study (although relevant policy papers were reviewed). On a more positive note, the findings were based on information gathered from local council staff working in areas directly related to policy, local environmental and community development. Another strength of the study is that perspectives were gathered from five of the seven councils.

In conclusion, the study findings emphasise on the consolidation of the goals of SWSLHD with that of Councils; need for provision of public health evidence that has local applicability in a timely manner on issues of mutual concern, and proactive and ongoing consultations between SWSLHD and councils would enable effective engagement, coordinated and sustained actions.

\section{Declarations}

Ethics approval and consent to participate: This study was approved by the Human Research Ethics Committee of South Western Sydney Local Health District (HE 16/069 LNR).

Consent for publication: The authors of this paper provide consent for publication of this paper in this journal.

Availability of data and materials: The qualitative data set which is stored in NVivo could be provided upon request. 
Competing interests: "All authors declare: no support from any organisation for the submitted work; no financial relationships with any organisations that might have an interest in the submitted work in the previous three years; no other relationships or activities that could appear to have influenced the submitted work."

Funding: This research was supported by Population Health, SWSLHD.

Authors' contributions: VK was responsible for the overall design of the manuscript. VK wrote the manuscript; all authors contributed towards critical review and approval of the final version. ZM and BJ were responsible for obtaining ethics committee approval. ZM was responsible for recruiting study participants, conducting interviews and data recording. VK was responsible for the data management, and analysis.

\section{Acknowledgements:}

The authors thank all the general managers and staff of councils who participated in this study. The authors also thank Mr Francis Fox for editing the paper. The authors also thank the all the coinvestigators of the project who contributed to develop the study protocol and obtain ethics approval. The authors acknowledge the support provided by Population Health, SWSLHD in conducting the study and writing the manuscript.

\section{References}

1. Bird EL, Ige JO, Pilkington P, Pinto A, Petrokofsky C, Burgess-Allen J. Built and natural environment planning principles for promoting health: an umbrella review. BMC Public Health. 2018;18(1):930.

2. Riesenberg D, Blake MR, Boelsen-Robinson T, Peeters A, Cameron AJ. Policies influencing the provision of healthy food and drinks in local government-owned sport and recreation facilities in Victoria, Australia. Aust N Z J Public Health. 2020;44(3):240-4.

3. NSW Ministry of Health. Healthy Built Environment Checklist. A guide for considering health in development policies, plans and proposals. Sydney: NSW Department of Health; 2020. Accessed on 20 April 2021. https://www.health.nsw.gov.au/urbanhealth/Pages/healthy-built-enviro-check.aspx.

4. Kite J, Thomas M, Grunseit A, Li V, Bellew W, Bauman A. Results of a mixed methods evaluation of the Make Healthy Normal campaign. Health Educ Res. 2020;35(5):418-36.

5. Kneale D, Rojas-García A, Thomas J. Obstacles and opportunities to using research evidence in local public health decision-making in England. Health research policy systems. 2019;17(1):61.

6. Javanparast S, Baum F, Freeman T, Ziersch A, Henderson J, Mackean T. Collaborative population health planning between Australian primary health care organisations and local government: lost opportunity. Aust N Z J Public Health. 2019;43(1):68-74.

7. Janzen C, Marko J, Schwandt M. Embedding health equity strategically within built environments. Canadian journal of public health = Revue canadienne de sante publique. 2018;109(4):590-7. 
8. Friel S, Akerman M, Hancock T, Kumaresan J, Marmot M, Melin T, et al. Addressing the social and environmental determinants of urban health equity: evidence for action and a research agenda. Journal of urban health: bulletin of the New York Academy of Medicine. 2011;88(5):860-74.

9. Bentley R, Blakely T, Kavanagh A, Aitken Z, King T, McElwee P, et al. A Longitudinal Study Examining Changes in Street Connectivity, Land Use, and Density of Dwellings and Walking for Transport in Brisbane, Australia. Environmental health perspectives. 2018;126(5):057003.

10. Parliament of New South Wales Government A. The Roles and Responsibilities of Federal, State and Local Governments. Accessed on 13.05.21 https://www.parliament.nsw.gov.au/about/Pages/TheRoles-and-Responsibilities-of-Federal-State-a.aspx 2021.

11. Janzen C, Marko J, Schwandt M. Embedding health equity strategically within built environments. Can J Public Health. 2018;109(4):590-7. doi:10.17269/s41997-018-0116-8.

12. Friel $S$, Akerman $M$, Hancock $T$, et al. Addressing the social and environmental determinants of urban health equity: evidence for action and a research agenda. J Urban Health. 2011;88(5):860-74. doi:10.1007/s11524-011-9606-1.

13. Chok HN, Thornell M, Maxwell M, Wise M, Sainsbury P. Population health services can influence land use planning. Aust N Z J Public Health. 2014;38(3):290-1.

14. Tong A, Sainsbury P, Craig J. Consolidated criteria for reporting qualitative research (COREQ): a 32item checklist for interviews and focus groups. International journal for quality in health care: journal of the International Society for Quality in Health Care / ISQua. 2007;19(6):349-57.

15. Braun Virginia CV. Using thematic analysis in psychology. Qualitative Research in Psychology. 2006;3(2):77-101.

16. Castleberry A. NVivo 10 [software program]. Version 10. QSR International. Am J Pharm Educ. 2014;12(78 (1))25.

17. Pettman TL, Armstrong R, Pollard B, Evans R, Stirrat A, Scott I, et al. Using evidence in health promotion in local government: contextual realities and opportunities. Health promotion journal of Australia: official journal of Australian Association of Health Promotion Professionals. 2013;24(1):72-5.

18. Office of Local Government-New South Wales of Australia. Community Engagement Strategy. Accessed on 13.05.21. https://www.olg.nsw.gov.au/councils/integrated-planning-andreporting/framework/community-engagement-strategy.

19. Preskill H, Parkhurst, Marcie S, Juster J,. The Guide to Evaluating Collective Impact by FSG. Accessed on 30.04.21. https://paulallen.ca/documents/2015/10/preskill-h-parkhurst-m-and-juster-js-learningand-evaluation-in-the-collective-impact-context-2014.pdf/. 2014. 